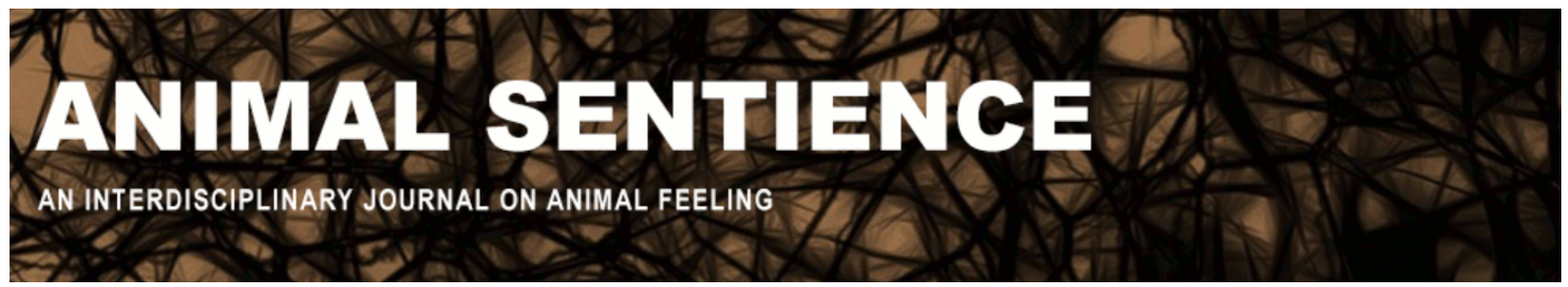

Bodily, Kent D. (2017) Reductionism and accounts of cognitive dissonance. Animal Sentience 12(10)

DOI: $10.51291 / 2377-7478.1276$

Date of submission: 2017-12-15

Date of acceptance: 2017-12-18 (c) 


\title{
Reductionism and accounts of cognitive dissonance
}

\author{
Commentary on Zentall on Cognitive Dissonance
}

\author{
Kent D. Bodily \\ Department of Psychology \\ Georgia Southern University
}

\begin{abstract}
Zentall (2016) proposed within-trial contrast as an alternative account of cognitive dissonance with greater parsimony and generalizability between human and nonhuman species. This commentary describes forms of reductionism, categorizes several competing accounts of cognitive dissonance phenomena, and addresses the strengths and weaknesses according to the reductionist form each account takes. A focus on functional relations may make explanation more parsimonious while bridging theoretical divides between human and nonhuman research programs
\end{abstract}

Kent D. Bodily is Associate Professor of Psychology at Georgia Southern University. His research focuses on mechanisms of learning and cognition in spatial navigation, reorientation, and choice. sites.google.com/a/georgiasouthern.edu/kdbodily/

Zentall (2016) proposed within-trial contrast as an alternative account of cognitive dissonance phenomena, particularly, justification of effort. In his thoughtful target article, he argued that within-trial contrast provides a more parsimonious account of cognitive dissonance phenomena while removing theoretical hurdles which divide human and nonhuman research programs.

Cognitive dissonance is a very successful meme (Dawkins, 2006). Festinger and Carlsmith (1959) alone has over 1,200 citations (according to Web of Science). The area encompasses at least four different general categories of situations. The concept of cognitive dissonance has also leapt from the pages of the primary literature to appear in introductory psychology textbooks, mass-media punditry, and even internet memes (captioned photos). The experimental designs have also been widely and systematically replicated and have successfully reproduced the expected effects. That is, when participants experience situations with particular characteristics, they respond in ways that are typical of dissonance-reduction. However, despite the fecundity of the cognitive dissonance meme and the reproducibility of the effects, there is little to no agreement when it comes to explaining the phenomena. Why, after six decades of empirical research, is there no agreed-upon mechanism?

The goals of natural science are to describe, predict and understand phenomena. A common approach to understanding is to reduce the complexity of observed phenomena to simple relationships between variables (Marr \& Zilio, 2013). Which classes of variables are admissible and which types of relationships are sought depend on the researcher and scientific paradigm they follow. The approaches can be categorized into two primary forms of reductionism (Nagel, 1979). Each form has inherent strengths and weaknesses (for more detailed treatment, see Marr \& Zilio, 2013). 
Heterogeneous Reduction: An Inter-level Synthesis. The most commonly considered form of reductionism involves attempts to explain relationships between events in one level of analysis by referring to events at another level of analysis. Using psychology as the focal level of analysis, heterogeneous reduction involves explaining behavioral phenomena by referencing hypothesized or observed events at an underlying level of analysis. Marr \& Zilio (2013) distinguished two types of heterogeneous reductionism. Mediational models explain observed relations between situations and behavior by referring to hypothetical constructs (see also MacCorquodale \& Meehl, 1948). Derivational principles, alternatively, connect observed relations between situations and behavior to observed neural activity.

The proposed accounts of cognitive dissonance phenomena are almost exclusively in the form of mediational models. The behavioral phenomena to be explained include persistence following belief disconfirmation; continuing to avoid a mildly forbidden activity; and changes in self-reported attitudes following mildly induced compliance, a difficult choice, or great effort. Mediational models explain these phenomena by referring to relationships between cognitions (Festinger \& Carlsmith, 1959; Harmon-Jones, Amodio, \& Harmon-Jones, 2009), the relationship between actions and self-concept (Aronson, 1999), or a relative value (Zentall, 2016; or value of the experimental context, Zentall \& Singer, 2007; or hedonic value, Zentall, 2005).

Mediational models serve as convenient tools to organize observations, develop research ideas, and make predictions. The formulation of mediational models is consistent with the use of metaphors in popular psychology, which increases accessibility to new students of the field. The hypothetical constructs used in mediational models tend to be vaguely defined, allowing broad application and interpretation.

However, vague constructs introduce surplus meaning (MacCorquodale \& Meehl, 1948) and, although proponents argue that they are a strength (see Harmon-Jones, Haslam \& Bastian, 2017), they may actually be a vice. Vagueness allows proponents of theories to explain away contradictory findings and limits a theory's ability to make clear predictions and prohibitions (Popper, 1963). The use of mediational models also leads to reification - treating the model as if it were the phenomenon of interest. In the case of cognitive dissonance, the name of the model is synonymous with the field of research. Referring to phenomena as "cognitive dissonance" or "justification of effort" is more than just a label - the label implies a mechanism. Finally, no mediational model can lay claim to parsimony, as they all refer to hypothetical constructs that themselves require explanation.

Homogeneous Reduction: Intra-Level Synthesis. An alternative approach is to reduce complex phenomena at one level of analysis to simple relationships occurring at that same level of analysis. This homogeneous reduction involves defining classes of events and identifying orderly, functional relationships between them. A common example of this type of reduction in psychology is defining the types of situations, classes of behavior, and classes of outcomes that make up the Law of Effect.

The proposed accounts of cognitive dissonance phenomena in the form of intra-level functional relations are limited, as far as this author can tell, to Bem (1967). The self-perception approach identifies and categorizes classes of stimuli (both situational and internal) and classes of behavior (including self-descriptive statements) to reveal functional relations between them. Similarly, Meindl (2012) explored the functional relations in the sequential chain procedure 
utilized by Zentall (2016) and colleagues (Clement, Feltus, Kaiser \& Zentall, 2000). In each of these accounts, the functional relations were reduced, essentially, to the Law of Effect. Dissonance occurs in the functional relations between behavior and situations.

Criticisms of homogeneous reduction in psychology include that it denies individual motivations, emotions and cognitions. Bem (1967) addressed these criticisms, as did Skinner (1974), but with little apparent success. Somehow, even if we can arrange a situation and predict with certainty a particular behavior, we continue to feel as if that functional relation requires an explanation rather than recognizing that it is an explanation.

What Is the Empirical Question? While writing this commentary, I serendipitously viewed "How Perspective Shapes Reality" (Reich, 2016). The video includes a description of how three competing quantum models were each derived from similar observations, produced equally valid mathematical descriptions, and all make the same experimental predictions. The narrator concludes that hence perhaps none of the models is correct. Kendler (1952) made a similar observation when reviewing contemporary learning theories:

"One may conclude that if comparable data are employed to support diverse answers to the same question, then the major source of difficulty lies not in the seemingly opposed answers but, rather, in the question itself. An analysis of the question is therefore in order." (p. 270)

Regarding the models of cognitive dissonance, over six decades of theoretical debate and thousands of peer-reviewed publications have failed to produce a broadly accepted model. Perhaps the failure to agree upon a model is revealing not of a shortcoming in the empirical research but of the absence of an empirical question.

The goals of natural science are to describe, predict and understand phenomena. Upon clearly describing and classifying the behavioral phenomena which fall under the traditional heading of "cognitive dissonance," we establish empirically the extent to which the phenomena can be predicted under various situations. But, how do we understand the phenomena? Must we develop psychological versions of phlogiston theory? Perhaps the way forward is to follow the advice of James (1890):

"the faculty does not exist absolutely, but works under conditions; and the quest of the conditions becomes the psychologist's most interesting task."

The conditions - the intra-level functional relations - are the understanding we seek. Persisting in homogeneous reduction leads to specificity of terminology and focus on orderliness of relations between classifications of situations, behaviors and outcomes. Moreover, weaning ourselves from reliance on mediational models meets Zentall's aspiration of more parsimonious explanation and fewer theoretical hurdles to connecting human and nonhuman research programs. 


\section{References}

Aronson, E. (1999). Dissonance, hypocrisy, and the self-concept. In E. Harmon-Jones \& J. Mills (Eds.), Science Conference Series. Cognitive Dissonance: Progress on a Pivotal Theory in Social Psychology (pp. 103-126). Washington, DC: American Psychological Association.

Bem, D. J. (1967). Self-perception: An alternative interpretation of cognitive dissonance phenomena. Psychological Review, 74(3): 183-200.

Clement, T. S., Feltus, J. R., Kaiser, D. H., \& Zentall, T. R. (2000). "Work ethic" in pigeons: Reward value is directly related to the effort or time required to obtain the reward. Psychonomic Bulletin and Review, 7(1): 100-106.

Dawkins, R. (2006). The Selfish Gene. New York: Oxford University Press.

Festinger, L., \& Carlsmith, J. M. (1959). Cognitive consequences of forced compliance. The Journal of Abnormal and Social Psychology, 58(2): 203-210.

Harmon-Jones, C., Haslam, N., \& Bastian, B. (2017). Dissonance reduction in nonhuman animals: Implications for cognitive dissonance theory. Animal Sentience 12(4).

Harmon-Jones, E., Amodio, D. M., \& Harmon-Jones, C. (2009). Action-based model of dissonance: A review, integration, and expansion of conceptions of cognitive conflict. Advances in Experimental Social Psychology, 41: 119-166.

James, W. (1890). The Principles of Psychology. New York: Henry Holt.

Kendler, H.H. (1952). "What is learned?"-A theoretical blind alley. Psychological Review, 59: 269-277.

MacCorquodale, K. \& Meehl, P. E. (1948). On a distinction between hypothetical constructs and intervening variables. Psychological Review, 55: 95-107.

Marr, M. J. \& Zilio, D. (2013). No island entire of itself: Reductionism and behavior analysis. European Journal of Behavior Analysis, 14: 241-257.

Meindl, J. N. (2012). Understanding preference shifts: A review and alternate explanation of within-trial contrast and state-dependent valuation. The Behavior Analyst, 35: 179-195.

Nagel, E. (1979). The Structure of Science. Indianapolis, IN: Hackett.

Popper, K. R. (1963). Conjectures and Refutations: The Growth of Scientific Knowledge. London: Routledge.

Reich, H. (2016). How Perspective Shapes Reality [Video file].

Skinner, B. F. (1974). About Behaviorism. New York, NY: Knopf.

Zentall, T. R. (2005). A within-trial contrast effect and its implications for several social psychological phenomena. International Journal of Comparative Psychology, 18: 273-297.

Zentall, T. R. (2016) Cognitive dissonance or contrast? Animal Sentience 12(1).

Zentall, T. R. \& Singer, R. A. (2007). Within-trial contrast: Pigions prefer conditioned reinforcers that follow a relatively more rather than a less aversive event. Journal of the Experimental Analysis of Behavior, 88: 131-149. 